\section{Kidney \\ Blood Pressure Research}

\title{
Inhibition of Autophagy Attenuated Ethylene Glycol Induced Crystals Deposition and Renal Injury in a Rat Model of Nephrolithiasis
}

\author{
Yunlong Liua Quan Liu ${ }^{a} \quad$ Xiang Wang ${ }^{a}$ Ziqi He ${ }^{a} \quad$ Derong Lia Xiaofeng Guana \\ Zhiwei Tao ${ }^{a}$ Yaoliang Denga,b \\ aDepartment of Urology, the First Affiliated Hospital of Guangxi Medical University, Nanning; \\ ${ }^{b}$ Department of Urology, the Langdong Hospital of Guangxi Medical University, Nanning, China
}

\section{Key Words}

Autophagy - Autophagic vacuoles - Calcium oxalate crystals $\cdot$ Renal tubular cells $\cdot$ Reactive oxygen species • Nephrolithiasis •

\begin{abstract}
Background/Aims: Nephrolithiasis is a common and frequently occurring disease, its exact pathogenesis is remains unclear. Emerging data suggest that autophagy plays a vital role in the pathophysiological processes of kidney diseases. Therefore, this study was designed to investigate the potential role of autophagy in the formation of calcium oxalate $(\mathrm{CaOx})$ kidney stones in rat model. Methods: Thirty-two rats were randomly divided into four groups (eight rats/group): untreated control group, stone model group, rapamycin-treated group, chloroquine-treated group. Rat models of $\mathrm{CaOx}$ nephrolithiasis was administration of $0.75 \%$ ethylene glycol (EG) in their drinking water for 4 weeks. Western blot and transmission electron microscope (TEM) were used to detect the expression of autophagy related protein LC3-II, BECN1 and p62 and autophagic vacuoles respectively. Renal function was evaluated by measuring the levels of serum CRE and BUN. Renal tubular injury markers NGAL and Kim-1 was determined by ELISA kits. Von Kossa staining was used to assess crystal deposits and histological tissue injury. TUNEL staining was employed to assess apoptosis of the renal tubular cell. Results: Compare with the controls, the expression of autophagy related protein LC3-II, BECN1 and number of autophagic vacuoles were increased significantly, whereas the p62 protein level was decreased in the stone model group. The levels of apoptosis, serum CRE and BUN, NGAL and Kim-1 in the stone model group were increased compared with the control group and crystals deposition and renal injury were increased significantly. However, the levels of autophagy, kidney injury and crystal deposition were decreased by
\end{abstract}

Y. Liu and Q. Liu contributed equally to this work and therefore share first authorship.

Yaoliang Deng

and Zhiwei Tao
Department of Urology, The First Affiliated Hospital of Guangxi Medical University

Nanning 530021, Guangxi Zhuang Autonomous Region (China)

Tel.+86-0771-5356516, E-Mail dylkf317@163.com,791562693@qq.com 


\section{Kidney \\ Blood Pressure Research}

Kidney Blood Press Res 2018;43:246-255

\begin{tabular}{|l|l|}
\hline DOI: 10.1159/000487678 & (C) 2018 The Author(s). Published by S. Karger AG, Base
\end{tabular}

Published onlıne: February 27, 2018 www.karger.com/kbr

Liu et al.: Inhibition of Autophagy Decreased Ethylene Glycol Induced the Formation of Nephrolithiasis

chloroquine but increased by rapamycin. Conclusion: These findings suggested that rats were administration of ethylene glycol could lead to the formation of $\mathrm{CaOx}$ nephrolithiasis and autophagy activation. Inhibiting autophagy could be an effective therapeutic approach for decreasing the formation of nephrolithiasis.

(C) 2018 The Author(s)

Published by S. Karger AG, Basel

\section{Introduction}

Nephrolithiasis is a complex disease, with a worldwide prevalence of about 1-5\% in Asia and $5-9 \%$ in Europe, which has a high recurrence rate of up to $50 \%$ within the subsequent 5-10 years [1-3]. Due to the high prevalence and recurrent of kidney stone disease, it seriously affected people's health and increased the financial burden to the healthcare system [4]. Approximately $80 \%$ of human kidney stones are predominately composed of calcium oxalate ( $\mathrm{CaOx}$ ) and oxalate is considered to be a major risk factor [5]. The formation of renal stones is mainly included by urinary supersaturation, crystal nucleation, growth, aggregation, and migration to renal epithelial cells surfaces [6]. Our recent studies demonstrated that exosomes might play a critical role in stone formation [7]. But so far, its exact pathogenesis is remains unclear.

Growing evidence suggests that autophagy is involved in physiological processes as well as in pathogenesis of many kidney diseases [8, 9]. Autophagy is a highly conservative regulatory system in which intracellular damaged organelles and protein aggregates are removed via the lysosomal degradation pathway $[10,11]$. The degraded cellular contents can be used for the synthesis of new essential macromolecules to maintain intracellular homeostasis [12]. Autophagy activity is usually triggered under stress conditions, which mainly including cell starvation, hypoxia, mitochondrial damage, endoplasmic reticulum (ER) stress, and oxidative stress, most of which are involved in the formation of calcium oxalate nephrolithiasis [13-15]. However, the role of autophagy in the development and progression of calcium oxalate kidney stones still remains poorly understand. This study aims to investigate the occurrence of autophagy induced by ethylene glycol in a rat model of nephrolithiasis, and then through using autophagy modulator to regulate the level of autophagy, so as to clarify the role and pathogenesis of autophagy in the formation of kidney stones.

\section{Materials and Methods}

\section{Reagents and antibodies}

Ethylene glycol (EG), chloroquine diphosphate (CQ), rapamycin (Rapa), 4',6-diamidino-2-phenylindole (DAPI) were purchased from Sigma-Aldrich. Rabbit anti-LC3B (2775), mouse anti-BECN1 (3495) and rabbit anti-p62 for Western blots were purchased from Cell Signaling Technology. Mouse anti-GAPDH (600041-Ig) was purchased from Proteintech. Mouse and rabbit HRP-conjugated antibodies were obtained from Zhong shan Golden Bridge.

\section{Animal modeling and treatment}

All animal experiments were approved by the Institutional Animal Care and Use Committee of Guangxi Medical University. A total of 32 adult male Sprague-Dawley rats, weighing 180-220 g, were used in the experiments. Rat models of calcium oxalate nephrolithiasis were established by administration of $0.75 \%$ ethylene glycol (EG) in their drinking water for 4 weeks. The rats were randomly divided into four groups (eight rats/group): untreated control group, stone model group, stone model treatment with rapamycin group, and stone model treatment with chloroquine group. Rats in the stone model+Rapa group and stone model+CQ group were intraperitoneally injected with rapamycin $(0.25 \mathrm{mg} / \mathrm{kg} / \mathrm{d})$ and chloroquine $(60 \mathrm{mg} /$ $\mathrm{kg} / \mathrm{d})$, respectively [16]. 


\section{Kidney Blood Pressure Research}

\begin{tabular}{|c|c|}
\hline \multicolumn{2}{|c|}{ Kidney Blood Press Res 2018;43:246-255 } \\
\hline $\begin{array}{l}\text { DOI: } 10.1159 / 000487678 \\
\text { Published online: February } 27,2018\end{array}$ & $\begin{array}{l}\text { (c) } 2018 \text { The Author(s). Published by S. Karger AG, Basel } \\
\text { www.karger.com/kbr }\end{array}$ \\
\hline
\end{tabular}

Kidney Blood Press Res 2018;43:246-255

Nephrolithiasis

At the end of the study, blood samples were collected from the inferior vena cava of rats under ether anesthesia. Serum levels of creatinine and blood urea nitrogen were determined using an automatic clinical chemistry analyzer (Hitachi 7600, Tokyo, Japan).

Enzyme linked-immunosorbent assay (ELISA)

After 4 weeks of treatment, $24 \mathrm{~h}$ urine samples were collected in metabolic cages to measure neutrophil gelatinase-associated lipocalin (NGAL) and kidney injury molecule 1 (Kim-1) levels by using ELISA kits (Cusabio Biotech, Newark, DE, USA) according to the manufacturer's instructions.

\section{Western blotting}

In brief, proteins from kidney tissues were obtained by use of RIPA lysis buffer, supplemented with $1 \mathrm{mM}$ PMSF. The protein concentrations were determined by a bicinchoninic acid (BCA) protein assay. Equal amounts $(50 \mu \mathrm{g})$ of protein samples were separated by $12 \%$ SDS-PAGE, and the protein bands were transferred onto PVDF membranes. After blocking with 5\% non-fat milk in TBS for $1 \mathrm{~h}$ at room temperature, the membranes were incubated with primary antibodies overnight at $4^{\circ} \mathrm{C}$. After washes, membranes were incubated with the appropriate peroxidase-conjugated anti-mouse/rabbit IgG for $1 \mathrm{~h}$ at room temperature. Chemiluminescent signals were captured by a CCD camera in a chemiDoc XRS (Bio-Rad) instrument with Image Lab software.

\section{In situ TUNEL fluorescence staining assay}

The terminal deoxynucleotidyl transferase-mediated dUTP nick end labeling (TUNEL) assay was employed to assess apoptosis of the kidney, according to the manufacturer instructions (Roche, Mannheim, Germany). TUNEL-positive cells were counted in five random fields under the fluorescence microscopy at a magnification of 400x. The apoptotic index was expressed as the percentage of TUNEL-positive cells of the total cell nuclei in each field.

\section{Histological Analysis}

After 28 days, the rats were euthanized, and the right kidneys were fixed with $4 \%$ paraformaldehyde and embedded in paraffin. Von Kossa staining was used to assess crystal deposits and histological tissue injury according to the manufacturer's instructions. The left kidneys were used for morphological or histopathological study.

\section{Transmission Electron Microscope}

The kidney specimens from rats were fixed with $2.5 \%$ glutaraldehyde at $4^{\circ} \mathrm{C}$, followed by treatment with $1 \%$ osmium tetroxide, then dehydrated and embedded in epoxy resin. Ultrathin sections were stained with uranyl acetate and lead citrate, and subsequently examined with a Hitachi-7650 transmission electron microscope (Hitachi Instrument, Tokyo, Japan). Quantification of autophagic vesicles was performed as described previously [17].

\section{Statistical analysis}

All the statistical analyses were performed using SPSS 20.0 software. All data were expressed as means \pm SEM of three different experiments. Student's $t$ test was used to compare two independent groups. Multiple comparisons were performed with a one-way analysis of variance (ANOVA), followed by Dunnett post-hoc tests. A value of $\mathrm{P}<0.05$ was considered statistically significant.

\section{Results}

Expression of autophagy-related proteins LC3-II, BECN1 and p62

Compared with the controls, western blot analysis indicated that the protein expressions of LC3-II and BECN1 were significantly increased and the expression of p62 protein was significantly decreased in rat models of nephrolithiasis. Compared with the stone model 


\section{Kidney Blood Pressure Research}

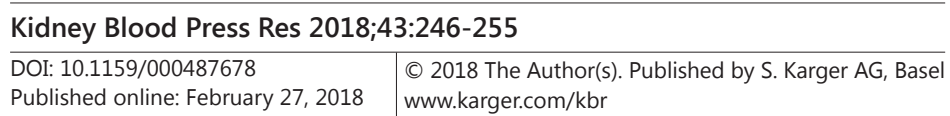

Liu et al.: Inhibition of Autophagy Decreased Ethylene Glycol Induced the Formation of Nephrolithiasis

group, treatment with chloroquine or rapamycin further increased the expression of LC3II, BECN1, while the expression of p62 protein was significantly increased and decreased, respectively (Fig. 1).

\section{Transmission Electron Microscopy observation}

As shown in Fig. 2, the autophagic vacuoles significantly increased in the stone model group compared with the controls. Compared with the stone model group, the number of autophagic vacuoles markedly increased in renal tissues from stone model treatment with chloroquine or rapamycin. In addition, TEM showed that mitochondria were swollen and damaged in the stone model group and rapamycin-treated group compared with the controls and the chloroquine-treated group (Fig. 2).

Fig. 1. Western blot analysis of the expression of autophagy-related proteins LC3-II, BECN1 and p62. A representative immunoblot and quantification analysis of LC3-II, BECN1 and p62 in renal tissues from the controls and stone model rats incubated with or without chloroquine (CQ 60 $\mathrm{mg} / \mathrm{kg} / \mathrm{d}$ ) or rapamycin (Rapa, 0.25 $\mathrm{mg} / \mathrm{kg} / \mathrm{d}$ ). Data are presented as the means \pm SEM from three experiments. ${ }^{*} \mathrm{P}<0.05,{ }^{* * *} \mathrm{P}<0.001$ versus the control group, ${ }^{\#} \mathrm{P}<0.05,{ }^{\# \# P}<0.01$ and ${ }^{\# \# \#} \mathrm{P}<0.001$ versus the stone model group.

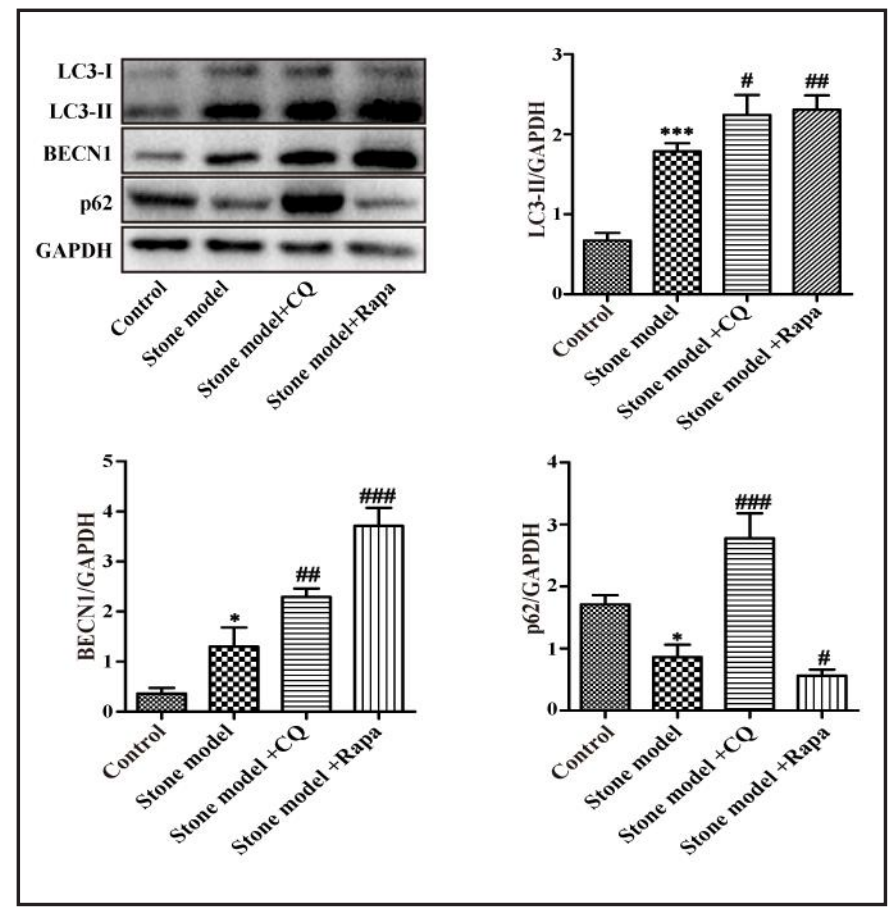

Fig. 2. Observation of autophagic vacuoles in renal tissue by transmission electron microscope. Representative transmission electronic micrographs showed a markedly increased number of autophagic vacuoles in renal tissues from stone model rats incubated with or without CQ or Rapa, compared with the controls. The number of autophagic vacuoles per $100 \mu^{2}$ was determined in transmission electron micrographs. Yellow and red arrows indicated autophagosomes and autolysosomes, respectively.

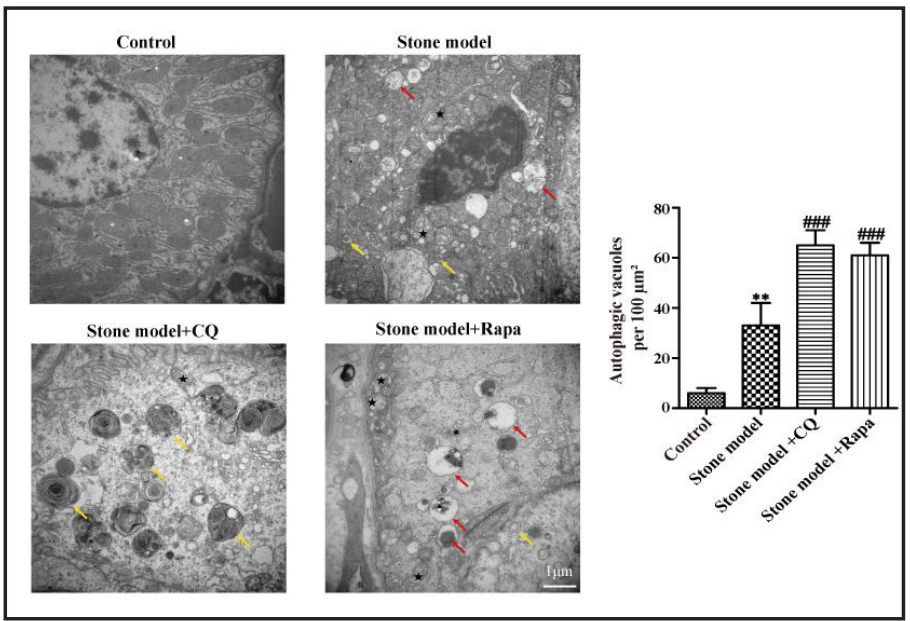
Black asterisk indicated swollen and damaged mitochondria; scale bar: $1 \mu \mathrm{m}$. Data are presented as the means \pm SEM from three experiments. ${ }^{* *} \mathrm{P}<0.01$ versus the control group, ${ }^{\# \# \#} \mathrm{P}<0.001$ versus the stone model group. 


\section{Kidney Blood Pressure Research}

Kidney Blood Press Res 2018;43:246-255

\begin{tabular}{l|c|c|}
\hline DOI: 10.1159/000487678 & ( 2018 The Author(s). Published by S. Karger AG, Basel \\
\hline
\end{tabular}

Published online: February 27, 2018 www.karger.com/kbr

Nephrolithiasis

\section{Changes of Renal Function}

In rat models of calcium oxalate nephrolithiasis showed a greater increase in the levels of serum CRE and BUN compared with the controls. Treatment with autophagy inhibitor chloroquine significantly decreased serum BUN and CRE levels, while autophagy activator rapamycin markedly increased the levels of CRE and BUN compared with the stone model group (Fig. 3).

\section{Detection of renal tubular injury markers NGAL and Kim-1}

To detect the effect of autophagy on kidney injury in the formation of calcium oxalate nephrolithiasis, we measured the release of urinary renal tubular injury markers NGAL and Kim-1. As shown in Fig. 4, the urinary NGAL and Kim-1 levels of the stone model group was increased significantly compared with the controls. The urinary levels of NGAL, Kim1 were further increased by rapamycin treated but significantly decreased after treatment with chloroquine.

Fig. 3. Changes of Renal Function. The levels of serum creatinine and urea nitrogen were determined using an automatic clinical chemistry analyzer. Data are presented as the means \pm SEM from three experiments. ${ }^{* *} \mathrm{P}<0.01$ versus the control group, ${ }^{\#} \mathrm{P}<0.05$ and ${ }^{\# \#} \mathrm{P}<0.01$ versus the stone model group.

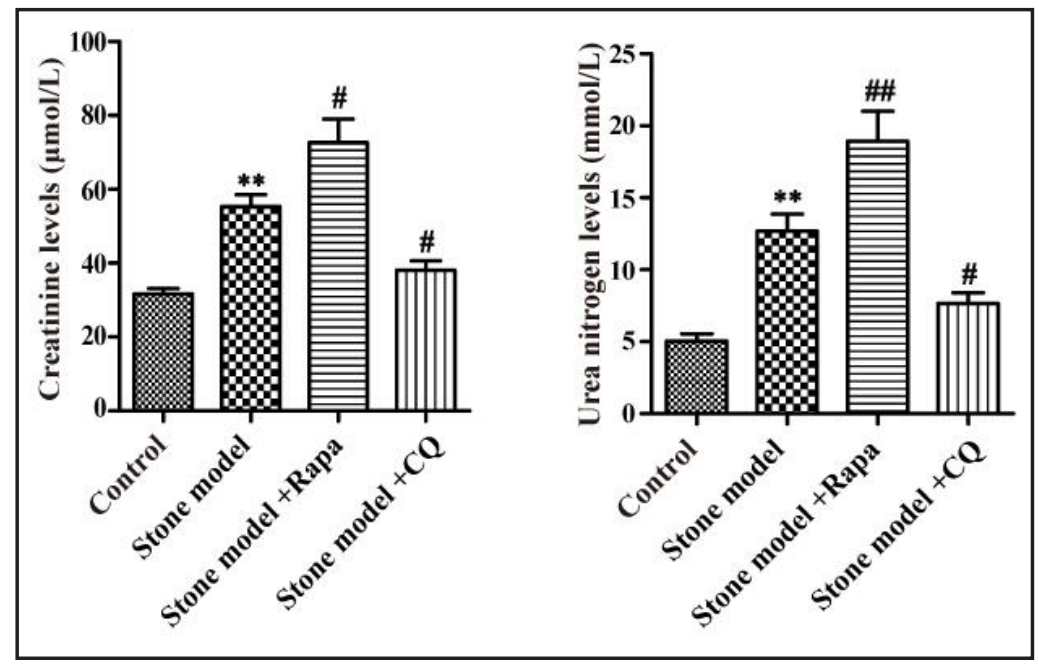

Fig. 4. Detection of renal tubular injury markers NGAL and Kim-1. The urinary NGAL and Kim-1 levels were measured by using enzymelinked immunosorbent assay (ELISA) kit. Data are presented as the means \pm SEM from three experiments. ${ }^{* *} \mathrm{P}<0.001$ and ${ }^{* * *} \mathrm{P}<0.001$ versus the control group, ${ }^{\#} \mathrm{P}<0.05$, ${ }^{\# \#} \mathrm{P}<0.01$ and ${ }^{\# \# \# P<0.001}$ versus the stone model group.

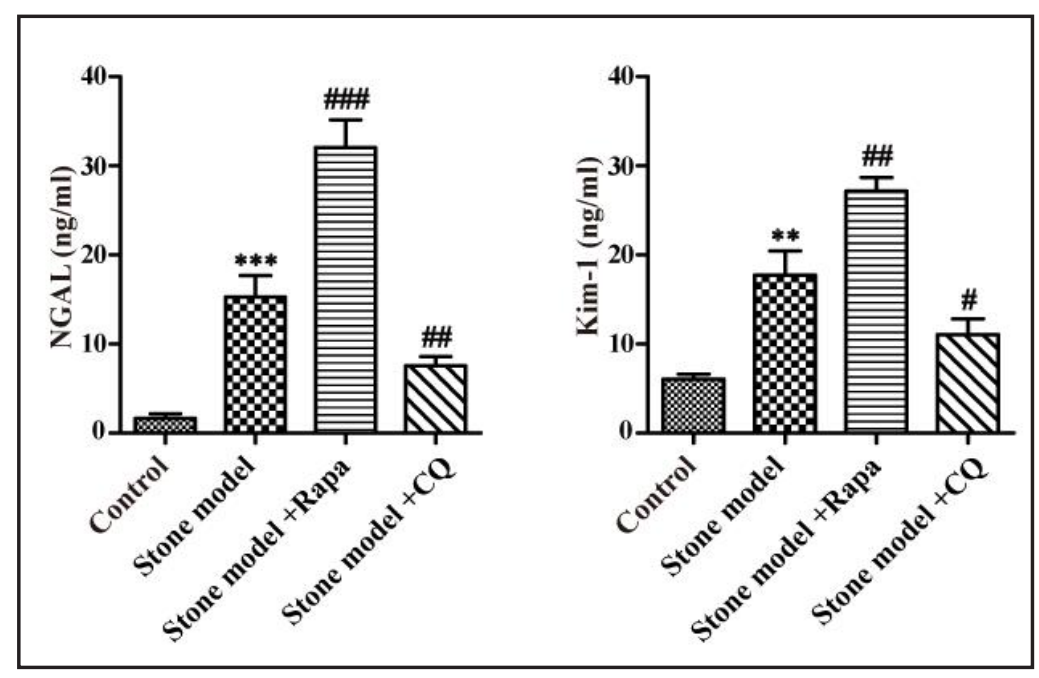




\section{Kidney Blood Pressure Research}

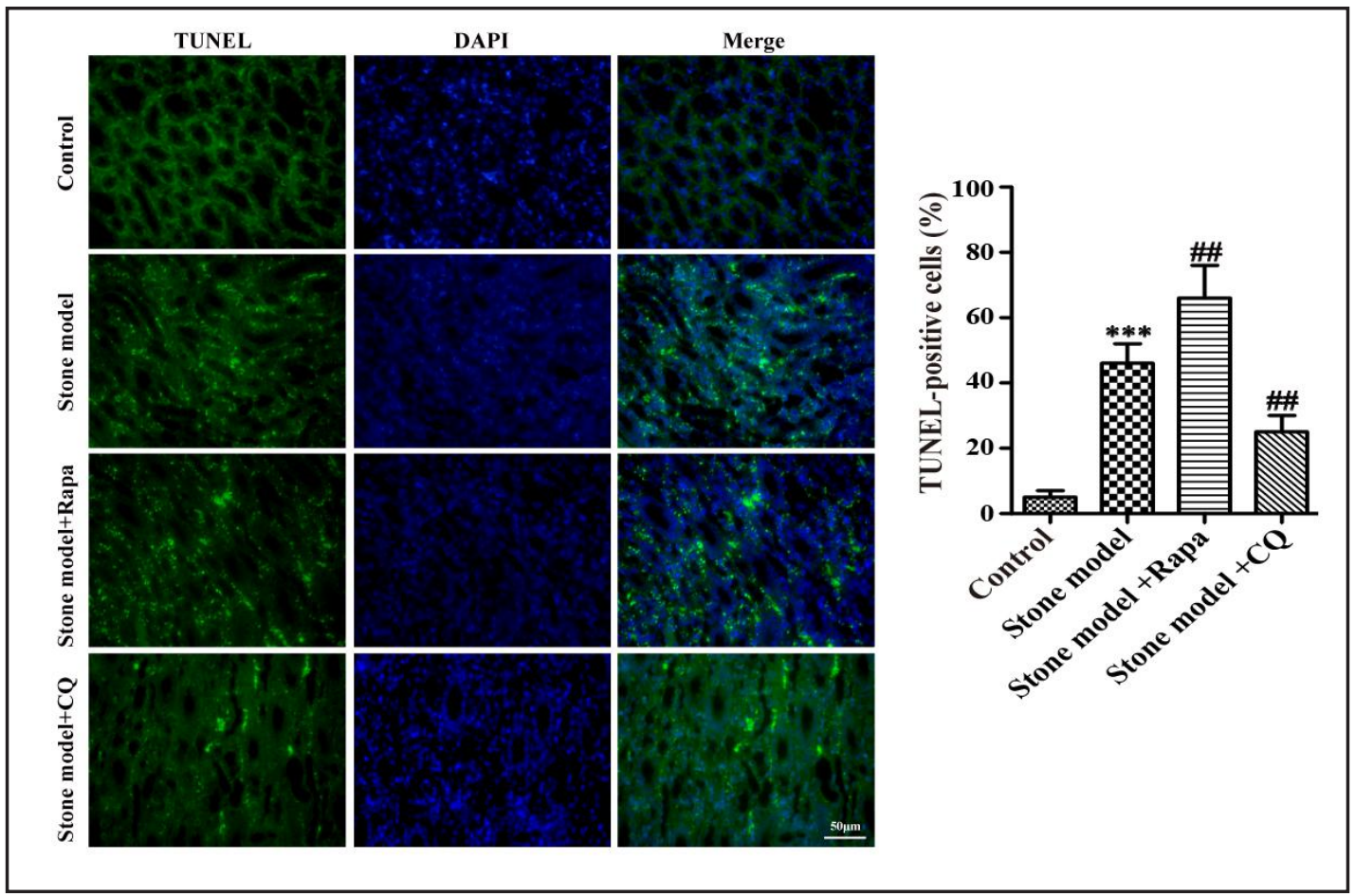

Fig. 5. Apoptosis detection. Representative TUNEL staining showed that the number of TUNEL-positive cells in renal tissues from the controls and stone model rats treated with or without rapamycin or chloroquine. Data are presented as the means \pm SEM from three experiments. ${ }^{* *} \mathrm{P}<0.001$ versus the control group, ${ }^{\# \#} \mathrm{P}<0.01$ versus the stone model group.

\section{Apoptosis detection}

To assess the effect of autophagy on renal tubular cell death in rat models of nephrolithiasis. TUNEL staining was employed to determine the percentage of apoptotic cells in renal slides. The number of TUNEL-positive cells were significantly increased in stone model group compared with control group. Furthermore, fewer apoptotic cells were observed in the chloroquine-treated group, whereas the rapamycin-treated group displayed more TUNEL-positive cells than the stone model group (Fig. 5).

\section{Analysis of crystals deposition and histopathological changes in kidney}

Von Kossa staining was used to assess CaOx crystal deposition and pathological changes in the kidney tissue. As shown in Fig. 6, a dramatic increase in crystal formation in the stone model group compared to control group. Moreover, we observed that there were more crystal deposits in cortical areas than in medullary areas. Kidney tissues in Von Kossa stained sections from the control group had a normal histological appearance, and no pathological changes was observed. In the stone model group, we observed that tubular dilatation and vacuolization, glomerular degeneration and edema. However, crystals deposition and histopathological changes were ameliorated by chloroquine but aggravated by rapamycin. In addition, we found that the size and the damage degree of the kidney was most visible in rapamycin-treated group compared to the stone model group or chloroquine-treated group (Fig. 7). 


\section{Kidney \\ Blood Pressure \\ Research}

Kidney Blood Press Res 2018;43:246-255

\begin{tabular}{|l|l|}
\hline DOI: $10.1159 / 000487678$ & (C) 2018 The Author(s). Published by S. Karger AG, Base
\end{tabular}

Published online: February 27, 2018 www.karger.com/kb

Liu et al.: Inhibition of Autophagy Decreased Ethylene Glycol Induced the Formation of Nephrolithiasis

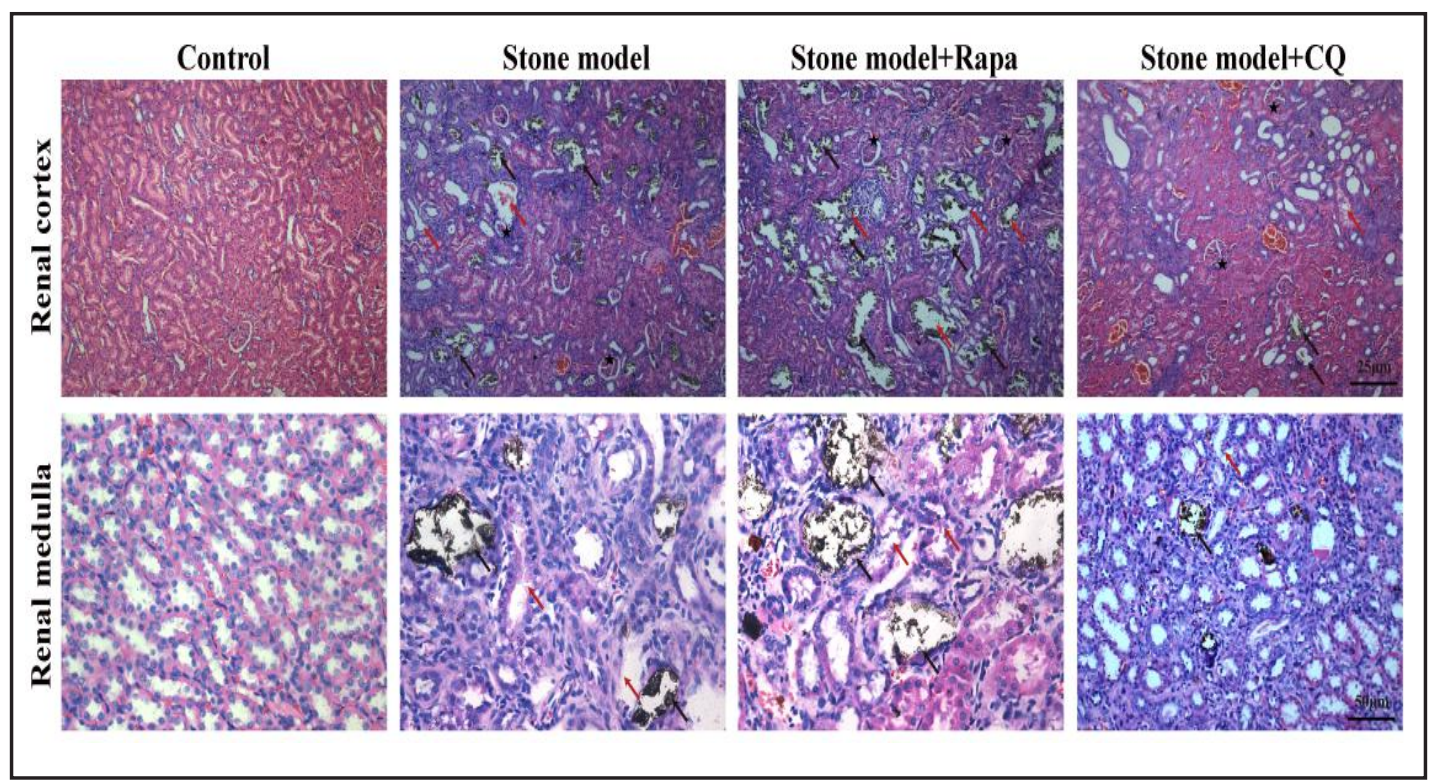

Fig. 6. Analysis of crystals deposition and histopathological changes in kidney. Representative Von Kossa staining showed that $\mathrm{CaOx}$ crystal deposition and renal tubular and glomerulus injury in the renal cortex and medulla. Black and red arrows indicated crystal deposition and renal tubular injury, respectively. Black asterisk represented swollen and damaged glomerulus; scale bar: $25 \mu \mathrm{m}$ and $50 \mu \mathrm{m}$.

\section{Discussion}

The present research provides compelling evidence for the first time for the occurrence of autophagy and its role in a rat model of calcium oxalate nephrolithiasis. Our results showed that the induction of autophagy in this model was evaluated by immunoblot analysis of autophagy-related proteins LC3-II, BECN1 and p62 expression, and transmission electron microscopic detection the formation of autophagic vacuoles. We subsequently found that the level of autophagy could be effectively regulated by chloroquine or rapamycin in rat models of $\mathrm{CaOx}$ nephrolithiasis. Emerging data suggest that autophagy can play a pro-survival or pro-death role under different pathological conditions $[18,19]$. Intriguingly, we observed that raising the level of autophagy by rapamycin further increased the levels of $\mathrm{Cr}$ and $\mathrm{BUN}$, the

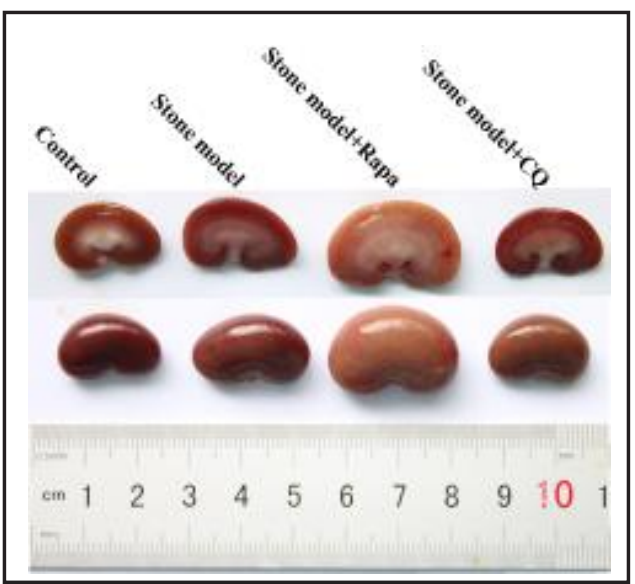

Fig. 7. Analysis of pathological histology of kidney. A representative image showing the size and the damage degree of the kidney was most visible in rapamycin-treated group compared to the stone model group or chloroquinetreated group. excretion of NGAL and Kim-1, the number of TUNEL-positive cells, and CaOx crystal deposition and renal tubular injury in rat models of $\mathrm{CaOx}$ nephrolithiasis. However, treatment with autophagy inhibitor chloroquine significantly decreased the levels of the above indicators in stone model. In addition, we have previously demonstrated that autophagy was deleterious in $\mathrm{CaOx}$ crystal-induced renal tubular epithelial cell injury [20]. Therefore, we inferred that autophagy activation may be further promoted the formation of CaOx kidney stones.

Kidney injury molecule-1 (Kim-1) is a type 1 transmembrane glycoprotein, and its expression is significantly increased in proximal tubule epithelial cells following renal injury [21]. Neutrophil gelatinase associated lipocalin (NGAL) is a 25-kDa protein of the lipocalin 


\section{Kidney \\ Blood Pressure Research}

Kidney Blood Press Res 2018;43:246-255

\begin{tabular}{l|l}
\hline DOI: $10.1159 / 000487678$ & (c) 2018 The Author(s). Published by S. Karger AG, Basel
\end{tabular}

Published online: February 27, $2018 \quad$ www.karger.com/kb

family, and it is widely used to detection the early renal tubular injury and/or dysfunction in kidney disease [22]. A growing number of studies have demonstrated that renal epithelial cells injury play a vital role in the development of CaOx nephrolithiasis [23, 24]. Some studies have reported that Kim-1 and NGAL were increased in urolithiasis patients [25, 26]. Therefore, we examined the effects of autophagy on Ox or CaOx crystal-induced renal tubular epithelial cell injury by measuring the levels of Kim-1 and NGAL.

Our previous studies demonstrated that hyperoxaluria and crystal deposition induced the production of ROS and renal epithelial cells injury in a rat model of calcium oxalate nephrolithiasis [27, 28]. Mitochondria are generally the most common intracellular sources of ROS, and cellular injury is usually accompanied by the production of ROS[29]. Veena and colleagues found that mitochondria were swollen and damaged in an animal model of hyperoxaluria [30]. Our present results were consistent with the their studies demonstrating that mitochondrial injury was evident in the stone model group and rapamycin-treated group. However, the degree of mitochondrial damage was relieved after treatment with chloroquine in rat models of nephrolithiasis. In addition, mounting evidence shows that ROS production motivates autophagy activation [31-33]. Therefore, we inferred that hyperoxaluria and crystal deposition damaged the mitochondria and lead to the overproduction of ROS, and as a consequence will also increase the formation of cellular debris that may act as inducers promote crystallization of $\mathrm{CaOx}$ crystals by providing substances for their heterogeneous nucleation [6]. Meanwhile, ROS-mediated autophagy maybe aggravated renal injury and promoted the formation of stone.

Apoptosis and autophagy are two distinct self-degradation processes that have important roles in the regulation of cell survival and death. Recently, some research has revealed that apoptosis and autophagy often coexist in the same cell, and their pathways may have parallel upstream signals [34, 35]. BECN1/ATG6 is a component of the P13K complex that involved in the initiation of autophagy, which can interact with the antiapoptotic protein Bcl-2, and thereby regulating both apoptosis and autophagy [36, 37]. In the present study, we found that hyperoxaluria and crystal deposition could simultaneous induced the apoptosis and autophagy, and accompanied by upregulation of BECN1 in rat kidneys. Inhibition of autophagy could significantly alleviated $\mathrm{Ox}$ and $\mathrm{CaOx}$ crystal-induced renal tubular epithelial cell apoptosis.

Chloroquine (CQ) is a widely used durg for the treatment of malaria, systemic lupus erythematosus (SLE), rheumatoid arthritis (RA), malignancies, and other inflammatory diseases [38]. Which is also an autophagy inhibitor that blocks the fusion of autophagosomes and lysosomes, and thereby decreases autophagic flux [10]. In this study, we demonstrated that CQ could effectively inhibit $\mathrm{Ox}$ and $\mathrm{CaOx}$ crystal-induced autophagy, and significantly attenuated crystals deposition and renal injury in rat models of nephrolithiasis. These findings suggest that CQ may be used for attenuating renal injury and reducing the formation of kidney stones. Due to a long-term usage of which often causes some side effects, and thus this hypothetical viewpoint still needs to be confirmed in the future.

\section{Conclusion}

Our results indicated that rats were administration of ethylene glycol could lead to the formation of $\mathrm{CaOx}$ nephrolithiasis and autophagy activation. We further demonstrated that autophagy is essential for ethylene glycol induced crystals deposition and renal injury in a rat model of nephrolithiasis. Inhibiting autophagy could be an effective therapeutic approach for decreasing the formation of nephrolithiasis. However, impairing autophagy through knockdown of autophagy-related gene mouse models of stones still need to be studied in the future. 


\section{Kidney \\ Blood Pressure Research}

Disclosure Statement
Kidney Blood Press Res 2018;43:246-255

\begin{tabular}{|l|l|l|}
\hline DOI: $10.1159 / 000487678$ & (C) 2018 The Author(s). Published by S. Karger AG, Basel
\end{tabular}

Published online: February 27, 2018 www.karger.com/kbr

Liu et al.: Inhibition of Autophagy Decreased Ethylene Glycol Induced the Formation of Nephrolithiasis

All the authors declared no competing interests.

\section{Acknowledgements}

This work was supported by the National Natural Science Foundation of China (No. 81760127, 81360113, 30860280 and 30960455), the Guangxi Natural Science Foundation (No. 2017GXNSFAA198070).

\section{References}

1 Ramello A, Vitale C, Marangella M: Epidemiology of nephrolithiasis. J Nephrol 2000;13:S45-50.

-2 Pinduli I, Spivacow R, del Valle E, Vidal S, Negri AL, Previgliano H, Farias Edos R, Andrade JH, Negri GM, Boffi-Boggero HJ: Prevalence of urolithiasis in the autonomous city of buenos aires, argentina. Urol Res 2006;34:8-11.

3 Galvin DJ, Pearle MS: The contemporary management of renal and ureteric calculi. BJU Int 2006;98:12831288.

4 Hiatt RA, Dales LG, Friedman GD, Hunkeler EM: Frequency of urolithiasis in a prepaid medical care program. Am J Epidemiol 1982;115:255-265.

-5 Khan SR: Animal models of kidney stone formation: An analysis. World J Urol 1997;15:236-243.

-6 Tsujihata M: Mechanism of calcium oxalate renal stone formation and renal tubular cell injury. Int J Urol 2008;15:115-120.

-7 He ZQ Guan XF, Liu YL, Tao ZW, Liu Q, Wu JH, Deng YL: Alteration of exosomes secreted from renal tubular epithelial cells exposed to high-concentration oxalate. Oncotarget 2017;8:92635-92642. Mao S, Zhang J: Role of autophagy in chronic kidney diseases. Int J Clin Exp Med 2015;8:22022-22029. Kaushal GP, Shah SV: Autophagy in acute kidney injury. Kidney Int 2016;89:779-791.

10 Klionsky DJ, Abdelmohsen K, Abe A, Abedin MJ, Abeliovich H, Acevedo Arozena A, Adachi H, Adams CM, Adams PD, Adeli K: Guidelines for the use and interpretation of assays for monitoring autophagy (3rd edition). Autophagy 2016;12:1-222.

11 Mizushima N: Autophagy: Process and function. Genes Dev 2007;21:2861-2873.

12 Choi AM, Ryter SW, Levine B: Autophagy in human health and disease. N Engl J Med 2013;368:651-662.

13 He C, Klionsky DJ: Regulation mechanisms and signaling pathways of autophagy. Annu Rev Genet 2009;43:67-93.

-14 Abhishek A, Benita S, Kumari M, Ganesan D, Paul E, Sasikumar P, Mahesh A, Yuvaraj S, Ramprasath T, Selvam GS: Molecular analysis of oxalate-induced endoplasmic reticulum stress mediated apoptosis in the pathogenesis of kidney stone disease. J Physiol Biochem 2017;73:561-573.

15 Khan SR: Reactive oxygen species, inflammation and calcium oxalate nephrolithiasis. Transl Androl Urol 2014;3:256-276.

-16 Liu WJ, Luo MN, Tan J, Chen W, Huang LZ, Yang C, Pan Q Li B, Liu HF: Autophagy activation reduces renal tubular injury induced by urinary proteins. Autophagy 2014;10:243-256.

17 Ding WX, Ni HM, Gao W, Hou YF, Melan MA, Chen X, Stolz DB, Shao ZM, Yin XM: Differential effects of endoplasmic reticulum stress-induced autophagy on cell survival. J Biol Chem 2007;282:4702-4710.

18 Baehrecke EH: Autophagy: Dual roles in life and death? Nat Rev Mol Cell Biol 2005;6:505-510.

-19 Chen ZH, Wu YF, Wang PL, Wu YP, Li ZY, Zhao Y, Zhou JS, Zhu C, Cao C, Mao YY, Xu F, Wang BB, Cormier SA, Ying SM, Li W, Shen HH: Autophagy is essential for ultrafine particle-induced inflammation and mucus hyperproduction in airway epithelium. Autophagy 2016;12:297-311.

20 Liu YL, Li DR, He ZQ Liu Q Wu JH, Guan XF, Tao ZW, Deng YL: Inhibition of autophagy-attenuated calcium oxalate crystal-induced renal tubular epithelial cell injury in vivo and in vitro. Oncotarget 2018;9:45714582. 


\section{Kidney \\ Blood Pressure Research}

Kidney Blood Press Res 2018;43:246-255

\begin{tabular}{l|l}
\hline DOI: $10.1159 / 000487678$ & (c) 2018 The Author(s). Published by S. Karger AG, Basel
\end{tabular}

Published online: February 27, 2018 www.karger.com/kbr

Liu et al.: Inhibition of Autophagy Decreased Ethylene Glycol Induced the Formation of Nephrolithiasis

21 Yin C, Wang N: Kidney injury molecule-1 in kidney disease. Ren Fail 2016;38:1567-1573.

22 Bolignano D, Donato V, Coppolino G, Campo S, Buemi A, Lacquaniti A, Buemi M: Neutrophil gelatinaseassociated lipocalin (ngal) as a marker of kidney damage. Am J Kidney Dis 2008;52:595-605.

23 Khan SR: Renal tubular damage/dysfunction: Key to the formation of kidney stones. Urol Res 2006;34:8691.

24 Ouyang JM, Yao XQ Tan J, Wang FX: Renal epithelial cell injury and its promoting role in formation of calcium oxalate monohydrate. J Biol Inorg Chem 2011;16:405-416.

-25 Tasdemir M, Fucucuoglu D, Kucuk SH, Erol M, Yigit O, Bilge I: Urinary biomarkers in the early detection and follow-up of tubular injury in childhood urolithiasis. Clin Exp Nephrol 2017; DOI: 10.1007/s10157-0171436-3.

26 Kandur Y, Gonen S, Fidan K, Soylemezoglu O: Evaluation of urinary KIM-1, NGAL, and IL-18 levels in determining early renal injury in pediatric cases with hypercalciuria and/or renal calculi. Clin Nephrol 2016;86:62-69.

27 Li CY, Deng YL, Sun BH: Taurine protected kidney from oxidative injury through mitochondrial-linked pathway in a rat model of nephrolithiasis. Urol Res 2009;37:211-220.

28 Li CY, Deng YL, Sun BH: Effects of apocynin and losartan treatment on renal oxidative stress in a rat model of calcium oxalate nephrolithiasis. Int Urol Nephrol 2009;41:823-833.

29 Vakifahmetoglu-Norberg H, Ouchida AT, Norberg E: The role of mitochondria in metabolism and cell death. Biochem Biophys Res Commun 2017;482:426-431.

-30 Veena CK, Josephine A, Preetha SP, Rajesh NG, Varalakshmi P: Mitochondrial dysfunction in an animal model of hyperoxaluria: A prophylactic approach with fucoidan. Eur J Pharmacol 2008;579:330-336.

-31 Scherz-Shouval R, Shvets E, Fass E, Shorer H, Gil L, Elazar Z: Reactive oxygen species are essential for autophagy and specifically regulate the activity of atg4. EMBO J 2007;26:1749-1760.

32 Chen Z, Liu X, Ma S: The roles of mitochondria in autophagic cell death. Cancer Biother Radiopharm 2016;31:269-276.

-33 Kroemer G, Marino G, Levine B: Autophagy and the integrated stress response. Mol Cell 2010;40:280-293.

-34 Eisenberg-Lerner A, Bialik S, Simon HU, Kimchi A: Life and death partners: Apoptosis, autophagy and the cross-talk between them. Cell Death Differ 2009;16:966-975.

-35 Maiuri MC, Zalckvar E, Kimchi A, Kroemer G: Self-eating and self-killing: Crosstalk between autophagy and apoptosis. Nat Rev Mol Cell Biol 2007;8:741-752.

-36 Ciechomska IA, Goemans GC, Skepper JN, Tolkovsky AM: Bcl-2 complexed with beclin-1 maintains full antiapoptotic function. Oncogene 2009;28:2128-2141.

37 Pattingre S, Tassa A, Qu X, Garuti R, Liang XH, Mizushima N, Packer M, Schneider MD, Levine B: Bcl-2 antiapoptotic proteins inhibit beclin 1-dependent autophagy. Cell 2005;122:927-939.

-38 Olsen NJ, Schleich MA, Karp DR: Multifaceted effects of hydroxychloroquine in human disease. Semin Arthritis Rheum 2013;43:264-272. 